\title{
A DINÂMICA URBANA \\ DE CIDADES MÉDIAS DO INTERIOR \\ PAULISTA SOB 0 \\ ESTATUTO DA CIDADE
}

\author{
JEFFERSON O. GOULART \\ Eliana T. Terci \\ EsTEVAM V. OTERo
}

\begin{abstract}
R E S U M O O artigo examina o alcance do Estatuto da Cidade como novo marco regulatório da politica urbana brasileira a partir de estudo comparativo de processos contemporâneos em três cidades médias do interior paulista (Piracicaba, Bauru e Rio Claro). O estudo se faz mediante a análise de três dimensóes complementares: econômica, urbanistica e político-institucional. São constatados obstáculos endógenos e exógenos que têm condicionado as políticas urbanas e dificultado a aplicação dos indicativos dos Planos Diretores recém-aprovados. Apesar da expressiva incorporação formal dos instrumentos do Estatuto da Cidade, boa parte náo tem sido implantada ou não foi regulamentada, cenário que pode ser generalizado como predominante no país e que remete aos padröes contemporâneos do desenvolvimento regional e urbano.
\end{abstract}

P A L A V R A S - c H A V e Dinâmica urbana; cidades médias; estatuto da cidade; planos diretores participativos.

Este trabalho examina o alcance do Estatuto da Cidade como novo marco regulatório da política urbana brasileira a partir de estudo comparativo de correspondentes processos contemporâneos em três cidades médias do interior paulista (Piracicaba, Bauru e Rio Claro). A compreensão desse fenômeno se faz mediante parâmetros analíticos de múltiplas dimensōes, a saber: econômica, urbanística e político-institucional. Trata-se de análise preliminar de investigação que os autores vêm desenvolvendo sobre a temática, razão pela qual os resultados aqui apresentados são ainda provisórios. ${ }^{1}$

O texto está estruturado em três sessóes. Na primeira, "Estado, desenvolvimento e dinâmica urbano-regional”, são discutidos os principais aspectos e consequências da crise do modelo nacional-desenvolvimentista que conduziu as políticas macroeconômicas do Brasil até os anos 1980 e as medidas neoliberais na condução da superação da crise. Ademais, se considera o desenho político-institucional que marca essas mudanças, notadamente os aspectos relativos à estrutura federativa e ao status dos municípios quanto às politicas de regulaçáo urbana. Nesse contexto foi aprovado o Estatuto da Cidade (Lei Federal no 10.257, de 10/07/2001), marco regulatório que ampliou as prerrogativas dos municípios, passou a requerer participação da sociedade civil nas decisôes de políticas públicas e impôs a subordinação da lógica urbana à função social da cidade.

$\mathrm{Na}$ segunda parte, "Transformaçôes recentes na rede urbana brasileira e seus reflexos no planejamento urbano", são tratadas as mudanças atuais, com destaque

1 A pesquisa "Processos Contemporâneos de Desenvolvimento Urbano em Cidades Médias: Estatuto da Cidade, expansão imobiliária, engrenagem econômica e dinâmica decisória político-institucional [2001-2011]" tem financiamento da Fundação de Amparo à Pesquisa do Estado de São Paulo (FAPESP). Os autores são gratos aos pareceristas anônimos da RBEUR pelas indicações de aperfeiçoamento deste texto. 
para o desempenho das cidades médias no processo de desenvolvimento e seu papel no planejamento territorial, regional e urbano. Nesse contexto, apresenta-se a base empírica dos municípios estudados através de dados socioeconômicos que evidenciam sua participação na rede urbana brasileira.

$\mathrm{Na}$ terceira seção, "Estatuto da Cidade, Planos Diretores e a política urbana", são examinados os processos de revisão dos Planos Diretores das cidades selecionadas, identificando-se aproximaçôes e distanciamentos com os instrumentos preconizados pelo Estatuto da Cidade para avaliar o alcance do novo marco regulatório na dinâmica urbana. No final, são apresentadas algumas hipóteses explicativas provisórias sobre o lugar das cidades médias no desenvolvimento urbano contemporâneo e os constrangimentos e obstáculos das políticas urbanas dos Planos Diretores, de modo a evidenciar o potencial normativo dos enunciados do Estatuto da Cidade em contraponto com seus obstáculos fáticos.

\section{ESTADO, DESENVOLVIMENTO E DINÂMICA URBANO-REGIONAL}

A recessão mundial do final da década de 1970 atingiu o Brasil face à dependência do financiamento externo que sustentou seu processo de substituição de importaçôes, resultando em dramático endividamento externo e em pressão inflacionária que afetaram a capacidade estatal de fazer política econômica de longo prazo, comprometendo a reedição de um projeto nacional liderado pelo Estado. Em decorrência, as décadas seguintes ficaram marcadas pelas inúmeras tentativas de estabilização monetária, numa sucessão de planos fracassados de combate à inflação, com exceção do Plano Real (1994), cujo êxito foi alcançado com grande sacrifício para o crescimento da economia e do emprego em virtude dos juros elevados e do câmbio sobrevalorizado.

$\mathrm{Na}$ esfera da política urbano-regional, o colapso do projeto desenvolvimentista implicou o abandono das políticas de desconcentração produtiva, principalmente do II Plano Nacional de Desenvolvimento (PND), ao que se seguiu uma "não-política" de desenvolvimento regional e urbano que deu lugar à guerra fiscal entre estados e municípios, os quais, valendo-se de renúncia fiscal, disputavam parcos investimentos privados. Isto, somado à deseconomia de aglomeraçáo, não reverteu a desconcentraçáo em curso e alterou sensivelmente a geografia industrial de setores tradicionais da indústria, a exemplo do setor automobilístico, que se descentralizou da regiáo do $\mathrm{ABC}$ Paulista, e o de bens náo duráveis de consumo, que se deslocou em grande parte para o Nordeste (Coutinho, 2003).

A melhora dos preços internacionais no mercado mundial de commodities, somada à mudança na conduta da política econômica a partir de 2003 - com o Estado reassumindo seu papel na conduçáo da economia -, favoreceu a retomada do crescimento econômico. O lançamento de várias açôes, como a Política de Desenvolvimento Produtivo (PDP), o Programa de Aceleraçáo do Crescimento (PAC) e o Programa Minha Casa Minha Vida (PMCMV), dentre outros, e a conjuntura nacional propícia a novos investimentos, distinguiram as cidades médias como espaços privilegiados por suas vantagens relativas, notadamente mobilidade livre dos congestionamentos característicos das metrópoles, melhor qualidade de vida e implantação de novos arranjos produtivos, tais como os Polos Tecnológicos, os Arranjos Produtivos Locais (APLs), 
clusters etc. As possibilidades de agrupamento de empresas do mesmo setor produtivo e de implantaçáo de novos centros de pesquisa em universidades tornam o ambiente propício às inovaçóes e à competitividade determinada pelo padrão internacional (Amorim Fo; Serra, 2001, p.29).

Esse novo ambiente indica mudança na relação entre Estado e setor empresarial, a partir da qual se combinam um projeto público-privado de desenvolvimento local e a estratégia das empresas para a utilização de recursos locais, ou mesmo para a criação de novos arranjos que se colocam como alternativas às nefastas estratégias baseadas na guerra fiscal. Em análise crítica do contexto em que ocorrem essas mudanças, Harvey (1996) observa um esvaziamento do papel coordenador da esfera federal em favor da descentralização, dando lugar a uma nova abordagem na administração urbana: em lugar do gerenciamento característico dos anos 1960-70, avançam as práticas relativas ao empresariamento da gestão das cidades, as quais passam a ser reconhecidas pelo seu perfil empresarial em relação ao desenvolvimento econômico. ${ }^{2}$

Há, porém, um aspecto positivo da descentralização: mesmo submetida à lógica da acumulação, se o comando das cidades não se resumir à competição, mas à ideia de cidade como corporaçáo coletiva, pode emergir um sistema decisório democrático (Harvey, 1996, p.62). Essa condicionante está diretamente relacionada ao grau de competitividade interurbana, questáo que só pode ser mediada pelo planejamento, caso contrário as regras do mercado reduzem o caráter coletivo e o sentido democrático da gestão urbana.

É importante enfatizar uma característica do processo de descentralização que marca o período aqui aludido e destacado por Braga (2004) em virtude das implicaçóes para a gestão urbana, aspecto também observado por Harvey (1996) na Europa e nos EUA: trata-se da questão fiscal, na qual se observa mudança significativa na condução do processo de descentralização e que se traduz numa ambiguidade, pois, ainda que a Constituição de 1988 tenha consagrado a tendência descentralizadora nas esferas decisórias, na década de 1990 a equação se inverteu em favor da União e, por consequência, em detrimento de estados e municípios. Braga (2004) observa uma inversão de tendência em duplo sentido: i) aumento da carga tributária brasileira, que salta do patamar de $24 \%$ do PIB em 1991 para 36\% em 2003; e ii) redução da participação dos estados e municípios na arrecadação em virtude da forma como se fez a recuperação fiscal da Uniâo, com a criação ou elevação de alíquotas de tributos e contribuiçôes não compartilhados com as esferas subnacionais. Isto ocorreu simultaneamente à problemática intensificação do processo de municipalização das políticas sociais.

Arretche (1996) esclarece as razōes que estimularam a descentralização: crise fiscal e democratização. Ou seja, a descentralizaçáo foi a resposta à escassa capacidade orçamentária pública: "a distribuição das atribuições administrativas entre os diversos níveis de governo seria uma solução efetiva para os problemas orçamentários e de eficiência administrativa" (Arretche, 1996, p.76-77). A democratização é a outra faceta desse processo, pois, a despeito da crise fiscal, não se deve ignorar o caráter participativo e inclusivo que a descentralização proporciona como possibilidade de controle público. ${ }^{3}$

A Constituição de 1988 teve como marcas a desconcentração tributária em favor de estados e municípios, descentralização de atribuiçôes e competências sociais mais importantes e indução normativa à cooperação entre todos os níveis de governo que, contudo, não diminuíram a primazia da Uniāo (Arretche, 2009; Goulart, 2009; Souza, 2005). Mas essas mudanças institucionais ampliaram a autonomia dos municípios -
2 Para uma síntese dessa visão, ver Castells; Borja (1996). Para uma crítica desta concepção, ver Vainer (2000).

3 Sobre esse aspecto, ressalte-se a contribuição do catalão Jordi Borja, a quem se atribui a oportuna correlação entre descentralização e democratização. 
aliás, reconhecidos como entes federados soberanos - e, respectivamente, seu escopo decisório. As possibilidades de maior controle e regulação da produção do espaço urbano pelas municipalidades, resultado de um longo processo de descentralização, teve ponto alto na aprovação do Estatuto da Cidade (Lei Federal no 10.257/2001), marco institucional que regulamentou o Capítulo da Política Urbana da Constituição (Artigos 182 e 183).

As possibilidades abertas pela aprovação do Estatuto da Cidade residiam no poder que conferia às administraçóes municipais nas políticas de desenvolvimento urbano. Para efetivar o novo arcabouço legal urbano, os municípios deveriam elaborar seus Planos Diretores, os quais definiriam prioridades e objetivos aplicáveis, enfocando as questôes relacionadas à produção do espaço urbano.

Antes da análise empírica sobre o alcance desse novo instrumento de regulação do espaço urbano, cabe uma breve exposição da evolução recente da rede urbana brasileira para elucidar o papel das cidades médias e caracterizar a base empírica deste estudo.

\section{TRANSFORMAÇÕES RECENTES NA REDE URBANA BRASILEIRA E SEUS REFLEXOS NO PLANEJAMENTO URBANO}

A década de 1970 registra intensa reorganização do território econômico nacional, resultado do processo de realocaçáo industrial que altera as dinâmicas regionais brasileiras polarizadas pelo eixo Rio-São Paulo. A intensificação da interiorização da indústria fortaleceu o polo formado no interior do estado de São Paulo. A partir de então, observa-se a inflexão do fenômeno territorial com fortes implicaçôes demográficas e socioeconômicas, quando se inverte o ritmo de crescimento das grandes aglomeraçóes metropolitanas e acentua-se o dinamismo das cidades médias, indicando a reversáo da polarização representada por aquelas. A evolução da rede de cidades no sul e no sudeste contribuiu para a formaçáo de uma estrutura "hierarquicamente mais equilibrada" (Amorim Fo \& Serra, 2001, p.11).

A Política Nacional de Desenvolvimento Urbano (PNDU), capítulo do II PND, atribuía papel importante às cidades médias, particularmente na articulação entre os grandes centros e um conjunto de cidades de menor porte, integrando e polarizando amplas redes de cidades e aglomeraçóes urbanas que já apresentavam o potencial de converter-se em instrumentos de uma "política de desenvolvimento urbano-regional" (Braga, 2005, p.2241). Assim, as cidades médias integram as estratégias regionais, e no Sudeste buscouse a desconcentração das regiōes metropolitanas de Rio e São Paulo, com o consequente "reforço das cidades de porte médio" (Steinberger \& Bruna, 2001, p.45).

As diretrizes de interiorização do desenvolvimento foram constrangidas pela dinâmica econômica e sua tendência à concentração de investimentos: "a política urbana postulava desconcentração geográfica, mas a política econômica buscava um novo patamar de substituição de importaçóes, com ênfase nos setores de bens de capital e insumos básicos, que possuíam caráter reconcentrador" (Steinberger \& Bruna, 2001, p.46).

$\mathrm{O}$ reforço das cidades médias como polos secundários foi uma tentativa de reversão da contradição flagrante do II PND, buscando conciliar as vantagens da economia de aglomeração metropolitana com um desenvolvimento urbano e regional mais equilibrado. Esse processo de desconcentração se restringiu a uma porção do 
território nacional definido pelas cidades de Belo Horizonte-Uberlândia-Londrina/ Maringá-Porto Alegre-Florianópolis-São José dos Campos-Belo Horizonte, definindo um "novo polígono de aglomeração industrial", no qual estão inseridos os principais polos tecnológicos nacionais (Diniz, 1993, p.36-7).

Esse processo foi mais acentuado no interior paulista, que à época reunia algumas condiçóes fundamentais para essa transformação, muitas delas originadas nas peculiaridades históricas de seus processos de ocupação e desenvolvimento econômico. Cano (2008) identifica cinco fatores que induziram à desconcentração industrial em direção ao interior paulista e que caracterizam o fenômeno da "desconcentração concentrada": i) as deseconomias de aglomeração da metrópole; ii) as políticas estaduais de descentralização; iii) as políticas municipais de atraçáo industrial; iv) as políticas federais de incentivo às exportaçôes e o Proálcool; e v) os grandes investimentos federais em indústrias de base e em centros de pesquisa.

Ao longo do período 1970-2000, a Regiáo Metropolitana de São Paulo (RMSP) perdeu participação no Valor de Transformação Industrial (VTI) no conjunto da indústria brasileira, caindo de 43,4\% em 1970, para 16,8\% em 2003, ao mesmo tempo em que se observou crescente heterogeneidade no desenvolvimento das regióes brasileiras, despontando verdadeiras "ilhas" de produtividade. O maior beneficiado desse processo foi o interior paulista, em especial os municípios médios dotados de infraestrutura. No período entre 1970 e 1985, enquanto a participação da RMSP no VTI estadual declinava de $74,7 \%$ para $56,6 \%$, a participação do interior crescia de $25,3 \%$ para 43,4\% (Negri, 1996, p.181). Em relação ao conjunto do país, entre 1970 e 2003, o VTI do interior do estado quase dobrou, passando de $14,7 \%$ para 27\% (Tineu, 2008, p.383). Dados da Fundaçáo Seade indicam que o interior paulista concentrava, em 2011, 44\% do Produto Interno Bruto de todo o estado ou 15\% da riqueza nacional, além de responder por $44 \%$ do emprego no estado e $13 \%$ do país.

Esse processo teve correspondência em termos demográficos. Em 2010, as cidades do estado de São Paulo com população entre 100 mil e 500 mil habitantes, excluídas aquelas da RMSP, passaram de 21, em 1980, para 46 em 2010 (Braga, 2005), onde viviam 8.873.886 paulistas (Censo 2010/IBGE).

Harvey (1996) ajuda a compreender esse fenômeno como resultado da nova estratégia de gestão urbana predominante a partir da década de 1970. O empresariamento e consequente competição interurbana estáo na raiz da ascensão e decadência das cidades, ou seja, "encoraja determinados tipos de atividade e esforços que têm a maior capacidade localizada de elevar o valor das propriedades, da base tributária, da circulação local de renda e (a mais esperada das consequências da lista precedente) do crescimento do emprego" (Harvey, 1996, p.59).

Assiste-se, assim, a uma fecunda mudança nas "práticas espaciais". Chama atenção a difícil delimitação dos contornos do urbano, visto que simultaneamente ao crescente movimento de fragmentação do espaço em bairros, comunidades e grupos, a tecnologia aplicada aos transportes e às comunicaçóes permitiu maior dispersão do espaço, alterando o antigo "conceito de cidade enquanto unidade física rigidamente delimitada ou mesmo um domínio administrativo coerentemente organizado" (Harvey, 1996, p.51).

Nessas condiçóes, parece evidente que o empresariamento - na apropriada concepçáo de Harvey (1996), que indica a primazia do interesse privado com suporte das agências governamentais - foi o paradigma que conduziu a gestão urbana no 
período recente definindo as novas dinâmicas territoriais, coincidindo no Brasil com o esgotamento do projeto desenvolvimentista. Resta saber quais estratégias as delinearam, considerando os interesses empresariais e das municipalidades em razão dos elos que conectam regióes e localidades.

\section{Cidades médias no interior paulista: os casos de Piracicaba, Bauru e Rio Claro}

A partir dos anos 1980, as grandes açóes e políticas públicas com impacto na estrutura urbana e regional praticamente desapareceram. Estudos recentes confirmam que a ausência de políticas territoriais nacionais nesse período evidenciou experiências inovadoras de iniciativa das localidades. Estas, entretanto, não prescindem de uma política de cunho nacional, ou ainda, de compartilhamento entre as instâncias federativas, sobretudo pelo fato de a política urbana da Constituiçâo de 1988 haver consagrado essa premissa.

A recuperação do Estado, a partir da segunda metade da década de 1990, contudo, não significou a retomada das políticas territoriais e urbanas no padrão dos anos 1970, mas oscilaram entre uma orientação de crescimento econômico e outra mais preocupada com o desenvolvimento social (Bitoun, 2009). Normativamente, contudo, não é apropriado opor as opções social e econômica, "mas entender até que ponto o aumento do consumo e do protagonismo popular é visto como a alavanca principal ou acessória do desenvolvimento econômico do país" (Bitoun, 2009, p.22) e, nesses termos, tal premissa deve dar substância ao conceito de desenvolvimento humano e sustentável.

Nos anos 2000, a rede urbana brasileira passou a apresentar configuração mais complexa, apontando tendências importantes em termos de ocupação territorial e desenvolvimento socioespacial. Uma de suas principais características foi a crescente importância dos centros urbanos de médio porte, cujo impacto demográfico e econômico frente às aglomeraçóes metropolitanas e ao conjunto do país vêm se ampliando. Vejamos a seguir a evolução da base empírica adotada.

Piracicaba, Bauru e Rio Claro são cidades médias do interior paulista, exemplos da trajetória antes descrita. Em 1950, Piracicaba já somava 87.835 habitantes e era a $52^{\text {a }}$ cidade brasileira em população. Bauru tinha 65.452 residentes no mesmo período, ocupando a 89a posição. Em 1970 ambas evoluíram na rede brasileira: Piracicaba saltava para a $45^{\mathrm{a}}$ posiçáo, com 152.505 , e Bauru para a 56 , com 131.936 habitantes.

4 Desse processo resultaram os municípios de Itirapina, Itaqueri da Serra, Santa Gertrudes e Corumbataí.
Rio Claro deixou de figurar no ranking das 100 maiores, apresentando, em 1950, uma população em processo regressivo, devido à emancipação de alguns antigos distritos. ${ }^{4}$

$O$ peso relativo dessas cidades se confirma pelos dados atuais. Com uma populaçáo de 364.504 habitantes (Censo 2010/IBGE), taxa de urbanização de 97,33\%, vasta extensão territorial e alta concentração urbana, Piracicaba é um município de forte tradição na agroindústria canavieira e sede de um expressivo parque metal-mecânico. No plano político, a cidade abrigou importantes experiências progressistas: primeiro a administração do peemedebista João Hermann Netto ainda no fim do regime autoritário (1977-1982) e, depois, duas gestôes sob o comando do petista José Machado (1989-1992; 2001-2004). Neste último período foi levado a cabo o processo participativo para a revisão e formulação do novo Plano Diretor de Desenvolvimento Sustentável, encaminhado ao Legislativo municipal em 2004, proposta alterada e objeto de posterior substitutivo encaminhado pelo governo seguinte do tucano Barjas 
Negri (2005-2008).

Geograficamente localizada na porção central do estado, Bauru tem lugar privilegiado que lhe valeu a qualificação de "cidade sem limites", com população de 343.659 habitantes (Censo 2010/IBGE). Sua história está associada à expansão cafeeira ao oeste paulista, percurso para o qual o desenvolvimento da malha ferroviária foi determinante. Apresenta importante setor terciário, configurando expressiva polarização econômica e de serviços em nível regional, ao passo que seu parque industrial é relativamente modesto em comparaçáo com outros municípios de porte similar. Apresenta a mais alta taxa de urbanização dentre os três municípios: 98,5\%. Durante o mandato do prefeito Tuga Angerami, eleito pelo PDT (2005-2008), foi levada a cabo a mais relevante alteração na legislação urbanística municipal, quando um pioneiro processo participativo culminou com a aprovação do novo Plano Diretor inspirado nos instrumentos do Estatuto da Cidade.

Rio Claro - localizada às margens da rodovia Washington Luís, um dos mais importantes eixos paulistas de integração - apresenta população de 186.081 habitantes (Censo 2010/IBGE) e elevada taxa de urbanização (97,57\%). Sua economia é fortemente associada à atividade industrial dos setores metalúrgico e cerâmico, além do segmento de serviços. O atual Plano Diretor do município, ora em revisão, foi produzido durante o mandato do prefeito Dermeval da Fonseca Nevoeiro Jr. (DEM), marco legal que náo incorporou a metodologia participativa do Estatuto da Cidade.

Andrade e Serra (2001) revelam aspectos significativos da evolução dessas cidades no período 1975/96, tempo em que se verificou um arrefecimento da tendência de crescimento da economia brasileira. Os autores tomam por base o PIB estimado para os municípios brasileiros no período e concentram a análise nos 111 centros urbanos considerados de maior importância na rede brasileira de cidades em virtude de constituírem aglomeraçóes urbanas 5 . Naquela classificação de 1999, Bauru figurava como centro sub-regional de nivel 1 e Piracicaba como centro sub-regional de nivel 2, do qual Rio Claro fazia parte. ${ }^{6}$ De acordo com o estudo, esses 111 centros urbanos - os quais compunham um conjunto de 467 municípios - correspondem a $80 \%$ do total, e os demais 5.040 municípios brasileiros representam os $20 \%$ restantes. No intervalo considerado de 21 anos não se verificou alteração em sua participação no PIB nacional.

Observa-se, entretanto, uma relocalização das atividades produtivas, com perda de participação das metrópoles nacionais de São Paulo e Rio de Janeiro, com ganhos para as metrópoles regionais e centros regionais. Já os centros sub-regionais mantiveram sua participação, confirmando a já mencionada desconcentração concentrada. As taxas médias de crescimento do PIB para o grupo de municípios que compóem os centros sub-regionais "1" (à qual pertence Bauru) e "2" (à qual pertence Piracicaba) foram de $5,13 \%$ e $2,75 \%$, respectivamente. Considerando a taxa média brasileira, salta aos olhos o desempenho de Bauru, cuja taxa (5,13\%) esteve muito acima da nacional $(2,71 \%)$.

Tomando por base o comportamento do PIB per capita no período, observa-se a evolução dinâmica do centro sub-regional polarizado por Bauru, cuja taxa média de crescimento foi de 2,06\%, contrastando com Piracicaba, que foi de apenas $0,17 \%$. No centro representado por Piracicaba, o PIB per capita manteve-se praticamente constante durante o período 1975-96, enquanto o de Bauru aumentou em mais de 50\%. É preciso considerar, entretanto, que Bauru sai de um patamar bastante inferior ao de Piracicaba: enquanto o PIB per capita (média) do centro sub-regional de Piracicaba
5 Sobre o conceito de aglomerações urbanas, ver Braga, 2005, p.2244.

6 Os critérios para a hierarquização dos centros urbanos foram: centralidade, escala de urbanização, grau de complexidade e diversificação da economia urbana (Andrade; Serra, 2001). 
7 Para maiores informações sobre a hierarquia da rede de cidades brasileiras, ver "Regiões de Influência das Cidades 2007" (IBGE, 2008).

80 quesito Emprego \& Renda considera as variáveis geração de emprego formal, estoque de emprego formal e salários médios do emprego formal. era $\mathrm{R} \$ 7.556,00$ em 1975 , o de Bauru era $\mathrm{R} \$ 4.769,00$.

Tomando como referência a pesquisa realizada pelo IBGE para a elaboração das Regiôes de Influência das Cidades, de 2007, Piracicaba, Bauru e Rio Claro mantiveram papel destacado na rede urbana em virtude de sua força de atração em relação às cidades de seu entorno. Piracicaba e Rio Claro fazem parte da mesma aglomeração urbana, sendo que hierarquicamente Rio Claro está classificada como Centro Sub Regional $\mathrm{A}$, subordinado à rede de influência de Piracicaba, por sua vez classificada como Capital Regional C. ${ }^{7}$

Piracicaba e Rio Claro ainda estão vinculadas a Campinas, esta considerada Capital Regional A, que se interpóe entre aquelas cidades e São Paulo (Grande Metrópole Nacional). Bauru, por sua vez - classificada como Capital Regional C - faz o elo direto com São Paulo, o que confirma a inexistência de outra cidade de maior importância entre a "cidade sem limites" e a capital. Isto faz dela um polo importante na rede, e explica o alto peso relativo do setor de serviços $(79,8 \%)$ na composiçáo do Valor Adicionado do município ( $\mathrm{R}$ \$ 6.048.221), patamar muito acima da indústria $(19,9 \%)$ e da agropecuária $(0,3 \%)$.

Nos casos de Piracicaba e Rio Claro, o peso relativo da indústria na composição do Valor Adicionado é bem mais expressivo. Em Piracicaba a indústria tem participação de 42,3\% do Valor Adicionado, os Serviços 56,7\% e a Agricultura 1,0\%. No município de Rio Claro, o peso da indústria é ainda ligeiramente maior do que em Piracicaba, representando 46,4\%, inferior ao peso dos Serviços que representa 52,8\%; a Agropecuária representa apenas 0,8\% do Valor Adicionado. Comparando-se com números de 2000, pode-se observar que o crescimento do setor Serviços é uma tendência muito forte para Bauru, pois naquele ano o peso desse setor foi de $66,71 \%$, compondo com 32,28\% da Indústria, ou seja, o setor Serviços aumentou em mais de 50\% sua participação relativa. Em Piracicaba e Rio Claro, ao contrário, a variação foi pequena, ainda que a tendência de crescimento dos serviços seja verificável. Em todos os municípios é flagrante a queda de representação da Agricultura, que, em 2000, ainda ultrapassava a casa dos decimais, sendo que em Rio Claro a participação foi de 2,8\%, em Piracicaba 2,65\% e em Bauru 1,01\%.

Considerando-se a classificação do Índice Firjan de Desenvolvimento Municipal (IFDM) - o qual considera as três principais esferas indicativas de Desenvolvimento Humano para sua composição: emprego \& renda, educação e saúde com a mesma ponderação -, os municípios selecionados figuram entre os mais desenvolvidos do estado de SP e do Brasil em todos os anos, compondo os 31\% de municípios brasileiros de maior desenvolvimento. Todos saíram da situação de desenvolvimento moderado em 2000 para a situaçáo de alto desenvolvimento em 2007.

$\mathrm{O}$ fator que contribuiu para a situação de desenvolvimento moderado dos municípios em 2000 foi emprego \& renda ${ }^{8}$, o qual posicionou Rio Claro e Piracicaba na condiçáo de desenvolvimento regular neste quesito, contribuindo para puxar o IFDM para baixo. Rio Claro teve o melhor desempenho em 2000 (35 a posição estadual e 37 a nacional), alcançando alto desenvolvimento em educação e saúde, assim como Bauru. Piracicaba apresentou desenvolvimento moderado em Saúde naquele ano. Bauru foi o que melhor ascendeu no ranking, tendo saído da $72^{a}$ posição nacional e da $61^{\text {a }}$ estadual, em 2000, para o 23 e $24^{\circ}$ lugar, respectivamente, em 2007. A principal razão dessa melhoria foi o quesito emprego $\&$ renda. Piracicaba teve uma evoluçáo bastante significativa entre 2000 e 2007, quando sai da 269a nacional da $198^{a}$ estadual, em 
2000, alcançando o $73^{\circ}$ posto nacional e o $88^{\circ}$ estadual em 2007. Rio Claro recuou apenas uma posição no intervalo, ocupando em 2007 a 36 a posição estadual e a $38^{\text {a }}$ nacional. Vejamos a seguir em que medida esse desempenho socioeconômico traduz (ou não) a política urbana desenhada nos Planos Diretores dos municípios em análise.

\section{ESTATUTO DA CIDADE, PLANOS DIRETORES E POLÍTICA URBANA}

O Estatuto da Cidade regulamentou o capítulo II dos artigos 182 e 183 da Constituição e ampliou os poderes dos municípios para legislar sobre seus territórios. Para adequar as políticas urbanas, desencadeou-se um amplo processo de revisão dos Planos Diretores (PDs), incluindo mecanismos participativos nas decisóes públicas e subordinação da lógica urbana às funçóes sociais da cidade e da propriedade urbana.

Em Piracicaba, a revisão do PD teve início em 2002 (em substituição ao Plano de 1991 e vigente desde 1995), sob os seguintes princípios norteadores: i) direito à cidade sustentável; ii) pleno desenvolvimento das funçôes sociais da cidade e da propriedade; iii) combate à especulação imobiliária; iv) justa distribuição dos benefícios e ônus decorrentes do processo de urbanização; e v) gestão democrática da cidade (Pólis, 2003, p.15).

Ao longo do processo de expansão urbana - sobretudo durante o desenvolvimentismo dos anos 1960-70 - produziu-se um tecido fragmentado, com bairros distantes e descontínuos, habitados, sobretudo, pelas camadas mais pobres, e onde se via instalada uma dinâmica de exclusão socioespacial reforçada pela presença de inúmeros vazios urbanos. Cerca de $50 \%$ da área compreendida em seu perímetro urbano era representada por vazios urbanos, grande parte dotada de infraestrutura, obedecendo à lógica da especulação imobiliária. Essas constataçôes foram indicadas já no diagnóstico do processo, a partir das quais foi definido que o primeiro Eixo Estruturador do novo Plano seria "promover a destinação socioeconômica dos vazios urbanos e integrar socioterritorialmente os bairros da cidade” (Pólis, 2003, p.185-186).

Esse objetivo seria atingido por meio da correta aplicação dos instrumentos do Estatuto da Cidade, definindo-se o congelamento do perímetro urbano, priorizando-se a ocupaçấo dos vazios existentes. E assim o novo Plano Diretor foi aprovado em 2006, incorporando o mais avançado ferramental urbanístico para a indução, regulação e democratização da gestão urbana previsto no Estatuto. Isto não significou, contudo, sua efetiva aplicação de modo a intervir nas dinâmicas históricas de produção do espaço urbano local. O instrumento do "Parcelamento, Edificação ou Utilização Compulsórios" jamais foi regulamentado. O mesmo ocorreu com o "IPTU Progressivo no Tempo", "Direito de Preempção", "Outorga Onerosa" e "Transferência do Direito de Construir".

O Plano Diretor incorporou o instrumento das Zonas Especiais de Interesse Social (ZEIS) em duas modalidades: ZEIS 1, voltada à urbanização e regularização fundiária de áreas públicas e particulares ocupadas por assentamentos de baixa renda; e ZEIS 2, demarcadas em áreas não edificadas destinadas para a promoção de habitação popular (Art. 79). Estas foram regulamentadas em dezembro de 2009, por meio da LC 246/09, poucos meses após a constituição do Programa Minha Casa Minha Vida. Desde então foram descritas 21 ZEIS 2 em Piracicaba, principalmente na região norte da cidade, em área que no Macrozoneamento correspondia à Zona de Ocupação 
9 Integram o perímetro urbano as áreas urbanas contínuas do distrito sede de Piracicaba e do distrito de Santa Terezinha. Quando nos referirmos aos dados demográficos, estes se reportarão à totalidade da população do município, salvo quando identificado o recorte.
Controlada por Fragilidade Ambiental (ZOCFA).

As ZEIS 1 foram regulamentadas em dezembro de 2010, por meio da Lei Complementar (LC) 264/10. Nessa lei foram descritas as cinco áreas que correspondem às únicas ZEIS 1, a despeito do Plano Municipal de Habitação, elaborado em 2010, ter indicado a existência de 42 núcleos de favelas na cidade, onde viviam, segundo dados de 2005, 16.581 pessoas (PMHIS, 2010, pp.61;67). Outro instrumento regulamentado foi o Estudo de Impacto de Vizinhança, através da legislação municipal de uso e ocupação do solo (LC 208/2007), resultando na constituição do Grupo Interdisciplinar de Análise de Impacto de Vizinhança, que tem a competência de analisar os empreendimentos de impacto.

Dentre os instrumentos voltados à democratização da gestão urbana, o PD instituiu o Conselho da Cidade, com representação paritária entre representantes da administração municipal e da sociedade civil, com a missáo de apreciar e referendar matérias de "natureza urbanística e política urbana" (Art. 179).

A capacidade de o PD promover as adequadas funçóes sociais da cidade e da propriedade urbanas foi impactada negativamente por uma série de expedientes e circunstâncias: seguidas ampliaçóes do perímetro urbano, alteraçóes de índices urbanísticos e mudanças nos parâmetros de uso e ocupação do solo, assim como por decisôes de investimento de grandes corporaçóes multinacionais, para as quais as açôes do poder público municipal concorreram decisivamente. Esses fatores redundaram em alteraçôes na dinâmica urbana, constituindo e/ou reforçando tendências espaciais já constatadas no período de revisão do Plano Diretor.

Entre 1989 e 2000, o perímetro urbano ${ }^{9}$ foi ampliado em $17,16 \mathrm{~km}^{2}$, de 146,88 $\mathrm{km}^{2}$ (Lei Municipal 3108/1989) para 164,04 km² (LC 118/2000). Nesse período a população local passou de aproximadamente 275.650 (estimativa IBGE) para 329.158 habitantes (Censo 2000/IBGE) - acréscimo de 53.508 novos moradores.

Em 2010 Piracicaba contava, segundo dados do Censo do IBGE, com 364.872 habitantes. Entre este ano e 2004 (quando se propôs seu congelamento e que apresentava, à época, perímetro igual ao de 2000), o perímetro urbano foi ampliado em oito oportunidades, mais de uma vez por ano, passando dos já mencionados $164,04 \mathrm{~km}^{2}$ para $211,07 \mathrm{~km}^{2}$. Se acrescentarmos o perímetro da Zona Especial de Urbanização Específica - ZEUE Itaperú, definida pela LC 186/2006 e destinada à constituiçâo do Distrito Industrial Noroeste, e que após as modificaçôes da LC 261/2010 tornou-se contíguo ao perímetro urbano - seriam agregados $5,57 \mathrm{~km}^{2}$ a essa área. Portanto, considerando-se apenas a área urbana contínua do município, esta teve uma ampliação da ordem de 52,59 $\mathrm{km}^{2}$, representando um crescimento de pouco mais de $32 \%$, o que ampliou os vazios a $52 \%$ do perímetro urbano, em 2010, totalizando aproximadamente 11.000 hectares desocupados. Isto ocorreu a despeito de a ocupação dos vazios e o combate à retenção especulativa de terra urbanizada serem Eixos Estruturadores do Plano Diretor (Otero, 2011).

A segunda questão refere-se à atração de investimentos industriais por meio da concessão de incentivos variados, acompanhando a tendência de empresariamento da gestão urbana, a qual resultou na reformulação da legislação produzindo contradiçóes à política do PD. A partir da segunda metade dos anos 2000 instalaram-se dois grandes grupos industriais multinacionais, para o que se modificou a legislação urbanística para atender suas demandas. A LC 186/2006 instituiu o Distrito Industrial Noroeste, destinado à implantaçáo de uma grande planta industrial do segmento sucroalcooleiro, a qual representou ampliação do perímetro urbano da ordem de $5,57 \mathrm{~km}^{2}$, em área 
identificada pelo PD como não indicada à ocupação devido às fragilidades ambientais.

Em 2008, nova ampliaçáo do perímetro na região nordeste da cidade para a implantação do Parque Automotivo de Piracicaba, uma montadora de automóveis e indústrias de autopeças. $\mathrm{O}$ processo de relocalização industrial observa uma dinâmica própria, à semelhança dos anos 1970, mas percebe-se claramente que as políticas econômica e fiscal sobrepuseram-se e afetaram a política urbana.

Esse cenário autoriza deduçôes sobre a dinâmica recente de ocupação do solo urbano que resulta da reestruturação industrial, do empresariamento e do caráter político de gestão etc. Diferentemente das grandes expectativas suscitadas com o Estatuto da Cidade, observa-se determinantes vinculados à dinâmica econômica nacional que por vezes se sobrepóem às diretrizes expressas pelo planejamento urbano municipal.

Em Bauru, o processo de revisão do PD teve início em 2005, quando foram constituídas as equipes de trabalho incorporando integrantes da sociedade civil com o objetivo de garantir o processo participativo. Em conformidade com as diretrizes do Estatuto da Cidade, adotou-se uma metodologia que pressupunha: i) açóes internas de reuniáo de dados; ii) conhecimento do marco regulatório; iii) socialização das informaçôes e preparação dos agentes. Na sequência, deu-se início à elaboração do diagnóstico da cidade e formulação de propostas para definição dos eixos do novo Plano, com a participaçáo dos agentes comunitários. O projeto estruturado a partir das conclusōes da etapa anterior foi submetido à apreciação pública em reuniôes agendadas nos bairros e entidades, nas quais foram eleitos delegados para o Congresso da Cidade, realizado em março de 2006.

Essa experiência teve caráter inovador, tanto em relação aos processos anteriores dos Planos Diretores quanto em relação à tradição brasileira de planejamento, excludente e tecnocrática, privilegiando a manutenção da ocupação urbana em acordo com os interesses dos governos e das elites (Goulart, 2008).

$\mathrm{O}$ processo inclusivo trouxe à tona os problemas decorrentes de um processo de ocupação urbana que produziu uma cidade para poucos, diagnóstico que corrobora a análise produzida pela literatura sobre a cidade (Losnak, 2004). Seguindo a tradição brasileira, os esforços de modernização dos anos 1960-70 combinaram açóes industrializantes a obras suntuosas como abertura de avenidas, construçáo de viadutos e parques, produzindo uma versão moderna de cidade que concentrou os recursos de infraestrutura nas áreas ocupadas pelas elites locais e afastou os trabalhadores e as populaçóes pobres para autoconstrução na periferia, e/ou para os conjuntos da COHAB, lugares desprovidos até mesmo de condiçôes adequadas de acesso.

A aprovação legislativa do novo Plano Diretor Participativo enfrentou algumas dificuldades em razão da apatia política do governo para aprovar sua proposta. $\mathrm{O}$ projeto de lei hibernou na Câmara de Vereadores 23 meses, quando se transformou na Lei $n^{\circ} .5 .631$ de 22/08/2008, mesmo com alguns vetos do Executivo. Tais vetos se referiam, em especial, aos limites estabelecidos às construçóes, à verticalização e à expansão do perímetro urbano. Os questionamentos diziam respeito a aspectos da Outorga Onerosa, Parcelamento, Utilização e Edificação Compulsórios, Estudo de Impacto de Vizinhança e IPTU Progressivo, cujos critérios restritivos eram identificados como obstáculos ao desenvolvimento da cidade.

Um desses instrumentos, as Zonas Especiais de Interesse Social, merece especial comentário. O PD definiu as ZEIS e foi regulamentado através da Lei no 5.766/2009, a qual instituiu três modalidades: (1) "áreas de propriedade particular ocupadas por população de baixa renda, abrangendo favelas, onde existe interesse público na 
produção e na manutenção de habitaçôes de interesse social, incluindo equipamentos sociais e de geração de renda"; (2) "glebas ou lotes subutilizados, adequados a urbanização, onde existe interesse público em promover a produção e a manutenção de habitaçôes de interesse social, incluindo equipamentos sociais e de geração de renda"; e (3) "glebas ou terrenos públicos ocupados por favelas, áreas verdes ou institucionais, onde existe interesse público em promover a recuperação urbanística, a regularização fundiária, a produção e a manutenção de habitaçôes de interesse social, incluindo equipamentos públicos, comércio e serviço local, inclusive mini-distritos, sendo que neste caso, as mesmas deverão ser desafetadas e compensadas com outras áreas”. No total, foram indicadas oito ZEIS de tipo "1", outras onze de tipo "2" e mais doze de tipo "3". A análise das ZEIS permite interpretar o impacto do marco regulatório na promoção de habitaçóes de interesse social, além de examinar sua efetividade na dinâmica de produção do espaço urbano.

No cômputo geral, o PD bauruense incorporou basicamente todas as ferramentas do Estatuto da Cidade (macrozoneamento, Outorga Onerosa, IPTU progressivo, Direito de Preempção, Estudo de Impacto de Vizinhança, Parcelamento, Edificação ou Utilização Compulsórios, Transferência do Direito de Construir e Consórcio Imobiliários etc.) e, embora alguns sejam autoaplicáveis e outros ainda demandem regulamentação não consumada, sintetiza uma legislaçáo bastante avançada. As dificuldades para efetivação desses instrumentos são de duas ordens: políticas e institucionais (que demandam decisão governamental com eventuais custos políticos) e urbanísticas (disponibilidade de recursos).

No plano da gestão democrática e participativa, o PD de Bauru é bastante avançado. Além de instituir o Instituto de Planejamento e Desenvolvimento de Bauru (Art. 254), ainda não efetivado, estabelece "a participação da população em todas as fases do processo de gestão democrática da Política de Desenvolvimento urbano e rural, mediante as seguintes instâncias de participação: Conferência do Município de Bauru; assembleias constituídas pelos Setores de Planejamento; audiências públicas e plenárias; iniciativa popular de projetos de lei, de planos, programas e projetos de desenvolvimento urbano e rural; conselhos municipais relacionados à política urbana e rural” (Art. 256).

Já em Rio Claro, o primeiro Plano Diretor foi aprovado somente no ano de 1992, por meio da Lei 2.492/1992, o qual vigorou até 2007, quando foi revisado e substituído pelo novo Plano (Lei no 3.806/2007), ainda em vigor. Essa revisão ocorreu no bojo do grande processo nacional de revisão e elaboração de Planos Diretores participativos municipais, liderado pelo Ministério da Cidade. Este Plano incorporou os instrumentos do Estatuto da Cidade de forma bastante limitada. O PD estabelece um Macrozoneamento para o município, sendo que as definiçóes sobre parâmetros urbanísticos de uso e ocupaçáo do solo deveriam ser regulamentadas posteriormente, mediante "Lei Municipal de Zoneamento Urbano", o que nunca ocorreu. Este fato dificultou a aplicação do Plano, uma vez que em diversos pontos o zoneamento vigente ainda se reportava ao PD de 1992.

Isto ajuda a explicar porque os poucos instrumentos de indução e regulação presentes no PD não foram regulamentados, caso do "Parcelamento, Edificação ou Utilização Compulsórios", "IPTU Progressivo no Tempo", "Direito de Preempção", "Transferência do Direito de Construir" e "Estudo de Impacto de Vizinhança". Os instrumentos da "Outorga Onerosa” e o "Consórcio Imobiliário" sequer figuram na lei.

As ZEIS foram incorporadas apenas para efeito de regularização de áreas ocupadas por moradias populares. Não havia previsão de ZEIS vazias para promoção de 
novas unidades habitacionais. Um dos poucos instrumentos efetivados foi o Conselho de Desenvolvimento Urbano (CDU), que teve papel destacado no processo de revisão desse Plano. Com a ocorrência de inúmeros conflitos, pouca abertura à participação popular e sem incorporar todos os instrumentos previstos no Estatuto da Cidade, o PD de 2007 teve sua revisáo proposta e aprovada pelos participantes da $3^{\text {a }}$ Conferência da Cidade de Rio Claro, realizada em janeiro de 2010 (PMRC, 2012).

Nesse mesmo ano a Secretaria de Planejamento, Desenvolvimento e Meio Ambiente solicitou ao arquiteto José Magalhães e ao advogado Paulo Lomar pareceres técnicos sobre Plano Diretor de 2007, de modo a orientar a revisão. Com o parecer dos consultores, o Executivo solicitou ao CDU o início da revisão do PD, a fim de adequá-lo aos princípios do Estatuto da Cidade. O CDU, em conjunto com a SEPLADEMA, realizou a revisão do Plano Diretor ao longo do ano de 2011.

A minuta do novo PD foi apresentada à população no início de 2012, por meio de uma série de reuniôes - tanto nos conselhos municipais quanto em alguns bairros da cidade - e audiências públicas. As leis de Parcelamento do Solo e do Zoneamento Urbano também passaram por revisão, promovendo assim uma significativa modificação no arcabouço legal urbano do município.

A minuta do projeto de lei contempla importantes mudanças, além de maior abertura ao debate com a sociedade local. As ZEIS passariam a ser classificadas em três tipos: ZEIS 1 - áreas vazias destinadas a empreendimentos habitacionais de interesse social; ZEIS 2 - voltadas à regularização de favelas e cortiços; e ZEIS 3 - voltadas à regularização de loteamentos clandestinos ou irregulares. Além disso, incorpora o instrumento da Outorga Onerosa, a ser posteriormente regulamentada em lei específica. De modo geral, o projeto de lei do novo PD incorpora os instrumentos do Estatuto da Cidade, contudo, o processo ainda não foi concluído, pois não foi encaminhado à Câmara de Vereadores. Ademais, sua aplicação remete a regulamentaçóes posteriores, o que o tornará pouco autoaplicável e dependerá da conduta do governo de turno.

Quadro 1 - Balanço Comparativo dos Planos Diretores

\begin{tabular}{|c|c|c|c|}
\hline $\begin{array}{l}\text { INSTRUMENTO DO } \\
\text { ESTATUTO DA CIDADE }\end{array}$ & $\begin{array}{c}\text { PIRACICABA } \\
{[\mathrm{PT}, \text { depois PSDB] }}\end{array}$ & $\begin{array}{l}\text { BAURU } \\
\text { [PDT] }\end{array}$ & $\begin{array}{l}\text { RIO CLARO } \\
\text { [DEM }]\end{array}$ \\
\hline Macrozoneamento & $\begin{array}{c}\text { Incorporado, } \\
\text { Lei no } 208 / 2007\end{array}$ & \begin{tabular}{|c|} 
Incorporado \\
(definidos coeficientes \\
máximo e mínimo)
\end{tabular} & Incorporado \\
\hline $\begin{array}{l}\text { Zonas Especiais de } \\
\text { Interesse Social (ZEIS) }\end{array}$ & $\begin{array}{l}\text { Incorporado, regulamentado } \\
\text { pela Lei } 246 / 2009\end{array}$ & \begin{tabular}{|c} 
Incorporado e \\
regulamentado pela Lei \\
$5.766 / 2009$
\end{tabular} & $\begin{array}{l}\text { Incorporado, náo } \\
\text { regulamentado }\end{array}$ \\
\hline Outorga Onerosa & $\begin{array}{l}\text { Incorporado, não } \\
\text { regulamentado }\end{array}$ & $\begin{array}{c}\text { Incorporado, } \\
\text { não regulamentado }\end{array}$ & Não incorporado \\
\hline IPTU Progressivo & $\begin{array}{l}\text { Incorporado, não } \\
\text { regulamentado }\end{array}$ & $\begin{array}{c}\text { Incorporado, } \\
\text { não regulamentado }\end{array}$ & Náo incorporado \\
\hline Direito de Preeempçáo & $\begin{array}{l}\text { Incorporado, não } \\
\text { regulamentado }\end{array}$ & $\begin{array}{l}\text { Incorporado, } \\
\text { autoaplicável }\end{array}$ & $\begin{array}{l}\text { Incorporado, náo } \\
\text { regulamentado }\end{array}$ \\
\hline $\begin{array}{l}\text { Estudo de Impacto } \\
\text { de Vizinhança }\end{array}$ & $\begin{array}{c}\text { Incorporado, regulamentado } \\
\text { pela Lei } 208 / 2007\end{array}$ & $\begin{array}{l}\text { Incorporado, } \\
\text { autoaplicável }\end{array}$ & $\begin{array}{l}\text { Incorporado, nấo } \\
\text { regulamentado }\end{array}$ \\
\hline $\begin{array}{l}\text { Parcelamento, Edificação } \\
\text { ou Utilização Compulsória }\end{array}$ & $\begin{array}{l}\text { Incorporado, não } \\
\text { regulamentado }\end{array}$ & $\begin{array}{l}\text { Incorporado, } \\
\text { autoaplicável }\end{array}$ & $\begin{array}{l}\text { Incorporado, não } \\
\text { regulamentado }\end{array}$ \\
\hline $\begin{array}{c}\text { Transferência do Direito } \\
\text { de Construir }\end{array}$ & $\begin{array}{l}\text { Incorporado, não } \\
\text { regulamentado }\end{array}$ & $\begin{array}{c}\text { Incorporado, } \\
\text { não regulamentado }\end{array}$ & $\begin{array}{l}\text { Incorporado, não } \\
\text { regulamentado }\end{array}$ \\
\hline
\end{tabular}




\begin{tabular}{|c|c|c|c|}
\hline Consórcio Imobiliário & $\begin{array}{c}\text { Incorporado, não } \\
\text { regulamentado }\end{array}$ & Não incorporado & Não incorporado \\
\hline
\end{tabular}

A propósito, o cenário de Rio Claro náo constitui um caso isolado: com base em resultados de pesquisa nacional de avaliação dos Planos Diretores do último período, observa-se que o "potencial dos instrumentos de política urbana do Estatuto da Cidade praticamente não foi aproveitado e raramente os instrumentos de política fundiária foram plenamente regulamentados" (Oliveira, 2011, p.8), sendo sua regulamentação invariavelmente remetida à lei posterior específica.

Um exame comparativo dos instrumentos absorvidos pelos Planos nas três cidades aqui analisadas é sintetizado no Quadro 1, no qual se constata expressiva incorporação formal das ferramentas do Estatuto da Cidade, no entanto, sua efetivação é baixa face à ausência de regulamentação e a obstáculos de toda ordem: políticos, institucionais etc.

Registre-se finalmente que o entendimento sobre o caráter autoaplicável de um instrumento urbanístico (ou eventual necessidade de legislação complementar de regulamentação) pode provocar diferentes interpretaçôes jurídicas, de todo modo é imperativo que esteja inscrito no correspondente Plano Diretor.

\section{CONSIDERAÇÕES FINAIS: HIPÓTESES EXPLICATIVAS PRELIMINARES}

O processo de desconcentração regional promovido pelo II PND projetou as cidades médias no cenário econômico em detrimento das grandes aglomeraçôes metropolitanas, que tiveram sua importância diminuída devido ao significativo crescimento econômico e demográfico do interior do país. O destaque coube ao interior paulista, cujo conjunto já tem um peso na transformação industrial superior ao da RMSP.

Palco do "espraiamento espacial da riqueza nacional" nos últimos 40 anos, as cidades de porte médio foram o território desse importante crescimento econômico e demográfico, mas passaram a apresentar, ainda que em escalas distintas, grande parte dos problemas urbanos, físicos e sociais antes visíveis apenas nas grandes aglomeraçóes.

$\mathrm{Na}$ última década, a tendência à expansão econômica e demográfica das cidades médias foi impulsionada pela tentativa de retomada do crescimento econômico, contudo, mantiveram-se as contradiçôes entre crescimento econômico e desenvolvimento urbano de tempos remotos (Rolnik; Klink, 2011). Em outros termos - não obstante um novo marco institucional (Estatuto da Cidade), políticas públicas ambiciosas (casos dos Programas de Aceleração do Crescimento e do Minha Casa Minha Vida), novos governos (de centroesquerda) e uma nova conjuntura (marcada por tentativas de retomada do crescimento) -, a acumulação capitalista contemporânea manteve o padrão de produção do espaço urbano caracterizado pela segregação socioespacial, de sorte que os grupos sociais historicamente alijados permaneceram apartados dos frutos do crescimento econômico, enquanto os interesses privados do mercado imobiliário conservaram sua influência e capacidade de pautar e modelar a estrutura espacial das cidades.

Os problemas urbanísticos resultantes dos processos de acelerado crescimento e desenvolvimento econômico observados nos municípios analisados nesse recorte empírico encontraram uma promissora resposta institucional com o Estatuto da 
Cidade, quando estes tiveram seus poderes ampliados para legislar sobre seus territórios, dispondo de uma série de instrumentos de regulação e ordenamento urbanístico.

A partir de entâo, a política urbana, normativamente, deveria subordinar-se ao princípio da função social da cidade e da propriedade, sendo o Plano Diretor seu instrumento central. Os municípios de Piracicaba, Bauru e Rio Claro passaram por profundas revisóes de seus arcabouços legais urbanos, adequando-os a tais premissas no bojo da grande campanha federal em prol dos Planos Diretores Participativos.

Observam-se, porém, diversos constrangimentos endógenos e exógenos (político -institucionais e econômicos, sobretudo) que vêm condicionando as políticas urbanas e dificultando a aplicação dos indicativos dos Planos Diretores recém-aprovados. Em Piracicaba, por exemplo, a análise de duas variáveis específicas de modificaçóes no Plano Diretor (expansão do perímetro urbano e investimentos industriais) indica que interesses econômicos do mercado imobiliário sobrepuseram-se às determinaçóes ali expressas, levando à sua alteração. Em Bauru, o Plano Diretor está em estágio relativamente mais avançado porque alguns instrumentos podem ser considerados autoaplicáveis, embora outros exijam regulamentação específica. Em Rio Claro, o processo está em fase mais atrasada em razão de nova revisão, resultante das limitações do processo anterior e mesmo da mudança governamental.

No quesito gestâo democrática, a experiência de Bauru se revelou a mais avançada, tanto porque se fez de maneira efetivamente mais participativa, como porque enuncia formas inovadoras como a "iniciativa popular de projetos de lei", mesmo que tenha caráter normativo e ainda não seja praticada. Nessa dimensão - que não pode ignorar as orientaçóes político-ideológicas de cada gestão e as mudanças governamentais -, Piracicaba se situa em uma posiçáo intermediária, enquanto Rio Claro teve o desempenho mais fraco (Goulart, 2012).

Ainda há um longo percurso para fazer valer os novos instrumentos do Estatuto da Cidade na promoção de uma cidade politicamente mais democrática e urbanisticamente mais justa e equilibrada, seja porque o tempo de implantaçáo de seus dispositivos ainda é efetivamente limitado, seja porque os constrangimentos político-institucionais não são de pequena monta, bastando observar que, não obstante a expressiva incorporação formal de seus instrumentos, boa parte náo tem sido implantada ou não foi regulamentada, ensejando um cenário em que ainda não são autoaplicáveis. Tal panorama não é exclusivo das cidades aqui analisadas, pelo contrário, predomina amplamente no país (Santos Jr. e Montandon, 2011).

Esse hiato entre enunciados normativos e a realidade que sugere evidente distanciamento dos princípios do Estatuto da Cidade requer necessariamente uma apreciação multidisciplinar, vale dizer, uma análise que considere as determinaçóes econômicas, o padrão de expansão urbanística do período recente e, também, os correspondentes processos decisórios, uma vez que o grau de participação societária e as escolhas das elites políticas são variáveis cruciais.

Os resultados aquém do esperado são indissociáveis do "poder dos grupos privados sobre a produção e a apropriação da cidade”, do caráter genérico e impreciso dos diagnósticos e das diretrizes dos novos Planos e da "baixa compreensão dos mecanismos de apropriaçáo privada da cidade e dos instrumentos de reforma urbana por parte dos técnicos e das lideranças dos movimentos populares" (Santos, 2011, p.277).

Por fim, é importante registrar que o cenário e as tendências indicam a continuidade das investigaçóes empíricas para produzir balanço comparativo mais substantivo,

\begin{abstract}
Jefferson 0 . Goulart é doutor em Ciência Política pela Universidade de São Paulo (USP); professor do Departamento de Ciências Humanas da Faculdade de Arquitetura, Artes e Comunicação da Universidade Estadual Paulista (FAAC/ UNESP); pesquisador do Centro de Estudos de Cultura Contemporânea (CEDEC), Brasil..E-mail: jgoulart@ faac.unesp.br.
\end{abstract}

Eliana T. Terci é economista; doutora em História Social pela Universidade de São Paulo (USP); professora do Departamento de Economia, Administração e Sociologia da Escola Superior de Agricultura Luiz de Queiroz (ESALQ) da USP, Brasil. E-mail: etterci@usp.br.

Estevam V. Otero é mestre $\mathrm{e}$ doutorando em Arquitetura e Urbanismo pela Universidade de São Paulo (USP); professor da Universidade Metodista de Piracicaba (UNIMEP), Brasil. E-mail: estevamotero@yahoo.com. 
principalmente das inter-relaçóes entre perfil econômico e desenvolvimento urbano dessas cidades para mensurar de forma mais consistente e conclusiva o potencial transformador do Estatuto da Cidade. Por ora, o avançado marco regulatório da politica urbana brasileira (ainda) esbarra em antigos e poderosos obstáculos.

\section{REFERÊNCIAS BIBLIOGRÁFICAS}

AMORIM Fo, O.; SERRA, R.V. Evolução e perspectivas do papel das cidades médias no planejamento urbano e regional. In: ANDRADE, T. A.; SERRA, R. V. Cidades Médias Brasileiras. Rio de Janeiro: IPEA, 2001.

; ríodo $1975 / 96$. In:

Análise do desempenho produtivo dos centros urbanos brasileiros no pe; . Cidades Médias Brasileiras. Rio de Janeiro: IPEA, 2001.

ARRETCHE, M. Intervenção do Estado e setor privado: o modelo brasileiro de política habitacional. Estado, Mercado e Habitação. Espaço \& Debates, ano X, nº. 31, p. 21-36, 1990.

BRAGA, R. Política urbana, política fiscal e pacto federativo: limites e perspectivas do Estatuto da Cidade no contexto da reforma do Estado. Anais do VII Seminário Internacional da Rede Iberoamericana de Investigadores sobre Globalização e Território. Rio de Janeiro: IPPUR-UFRJ, 2004 .

Cidades médias e aglomerações urbanas no estado de São Paulo: novas estratégias de gestão territorial. Anais do X Encontro de Geógrafos da América Latina. São Paulo: USP, 2005. Disponível em:

<http://www.rc.unesp.br/igce/planejamento/publicacoes/TextosPDF/rbraga13.pdf>. Acesso em: 16 de jul. 2011.

BRASIL. Estatuto da Cidade. Lei Federal 10.257 de 10 de julho de 2001.

. Estatuto da Cidade: guia para implementação pelos municípios e cidadãos: Lei 10.257, de 10/7/2001, que estabelece diretrizes gerais da política urbana. Brasília: Câmara dos Deputados, 2002.

BITOUN, J. Tipologia das cidades brasileiras e políticas territoriais: pistas para a reflexão. In: .; MIRANDA, L. (Org.). Desenvolvimento e Cidades no Brasil: contribuição para o debate sobre políticas territoriais. Recife: FASE/Observatório das Metrópoles, 2009.

CANO, W. Desconcentração produtiva regional do Brasil 1970-2005. São Paulo: Ed. Unesp, 2008.

CASTELLO BRANCO, M. L. Cidades médias no Brasil. In: SPÓSITO, E. S.; SPÓSITO, M. E. B.; SOBARZO, O. (Org.). Cidades médias: produção do espaço. São Paulo: Expressão Popular, 2006.

CASTElLS, M; BORJA, J. As Cidades como Atores Políticos. Novos Estudos CEBRAP, n. 45, São Paulo, julho de 1996.

COUTINHO, L. O desafio urbano-regional na construção de um projeto de nação. In: GONÇALVES, M. F; BRANDÃO, C. A.; GALVÃO, A. C. (Org.). Regiões e cidades, cidades nas regiôes. São Paulo: Ed. UNESP/ANPUR, 2003.

DINIZ, C. C. Desenvolvimento Poligonal no Brasil: nem desconcentraçáo, nem contínua polarização. Nova Economia, Belo Horizonte, UFMG, v.3, n. 1, setembro de 1993.

.; CROCCO, M. A. Reestruturação Econômica e Impacto Regional: o novo mapa da indústria brasileira. Nova Economia, Belo Horizonte: UFMG, v.6, n.1, jul.1996. 
GOULART, J. O. Participación política y nuevas demandas democráticas: Estatuto de la Ciudad y toma de decisiones en la gestión urbana. Proceedings of XXII World Congress of Political Science (IPSA). Madrid: IPSA, 2012.

. Da Constituição cidadã ao Estatuto da Cidade: políticas públicas democráticas no governo local. . (Org.). As Múltiplas Faces da Constituição Cidadã. São Paulo: Cultura Acadêmica, 2009.

. Estatuto da Cidade e Plano Diretor Participativo: instituiçóes contam e a política faz diferença. Cadernos IPPUR, Rio de Janeiro, UFRJ, ano XXII, n. 1, jan./jul. 2008.

HARVEY, D. Do gerenciamento ao empresariamento: a transformação da administração urbana no capitalismo tardio. Espaço \& Debates, Ano XVI, n. 39, p. 48-64, 1996.

IFDM - ÍNDICE FIRJAN DE DESENVOLVIMENTO MUNICIPAL. Federação das Indústrias do Estado do Rio de Janeiro. Vários anos: 2000, 2005, 2006 e 2007.

IBGE. Regiōes de Influência das Cidades 2007. Rio de Janeiro: IBGE, 2008.

IBGE Cid@des. Bauru-SP. Disponível em: <http://www.ibge.gov.br/cidadesat/painel/painel. php?codmun=350600 $>$. Acesso em 19 maio 2012.

. Piracicaba-SP. Disponível em: <http://www.ibge.gov.br/cidadesat/painel/painel.php?codmun=353870 >. Acesso em 19 maio 2012.

. Rio Claro-SP. Disponível em: <http://www.ibge.gov.br/cidadesat/painel/painel.php?codmun=354390>. Acesso em 21 maio 2012.

LOSNAK, C. J. Polifonia urbana: imagens e representaçôes/Bauru - 1950/1980. Bauru: Edusc, 2004.

NEGRI, B. Concentração e desconcentração industrial em São Paulo (1880-1990). Campinas: Ed. UNICAMP, 1996.

OLIVEIRA, F. L. Os Novos Planos Diretores Municipais Brasileiros: uma avaliação preliminar. Anais do XIV Encontro Nacional da ANPUR. Rio de Janeiro: ANPUR, 2011.

OTERO, E. V. Expansão Urbana no Município de Piracicaba entre 2000 e 2010: políticas públicas e atividade imobiliária. Anais do XIV Encontro Nacional da ANPUR. Rio de Janeiro: ANPUR, 2011.

PIRES, E. L. S. Mutaçốes Econômicas e Dinâmicas territoriais Locais: delineamento preliminar dos aspectos conceituais e morfológicos. In: SPÓSITO, E. S.; SPÓSITO, M. E. B.; SOBARZO, O. (Org.). Cidades médias: produçâo do espaço. São Paulo: Expressão Popular, 2006. PMHIS - Plano Municipal de Habitação de Interesse Social. Diagnóstico Habitacional.

Piracicaba: EMDHAP; Bonin \& Silva, 2010.

POLIS. Relatório 1 - Leitura Técnica e Participativa. Revisão do Plano Diretor de Desenvolvimento de Piracicaba. Piracicaba: Pólis, 2003.

ROLNIK, R.; KLINK, J. Crescimento econômico e desenvolvimento urbano: por que nossas cidades continuam tăo precárias?. Novos estudos - CEBRAP, São Paulo, n. 89, Mar. 2011. Disponível em: <http://www.scielo.br/scielo.php?script=sci_arttext\&pi$\mathrm{d}=$ S0101-33002011000100006\&lng=en\&nrm=iso $>$. Acesso em: 05 ago. 2013. (http://dx.doi. org/10.1590/S0101-33002011000100006).

SANTOS, M. R. M. O sistema de gestáo e participação democrática nos planos diretores brasileiros. In: SANTOS JR., O. A.; MONTANDON, D. T. (Org.). Os Planos Diretores Municipais pós-Estatuto da Cidade: balanço crítico e perspectivas. Rio de Janeiro: Letra Capital; Observatório das Metrópoles: IPPUR/UFRJ, 2011. p. 255-280.

SANTOS JR., O. A.; MONTANDON, D. T. (Org.). Os Planos Diretores Municipais pós-Esta- 
tuto da Cidade: balanço crítico e perspectivas. Rio de Janeiro: Letra Capital; Observatório das Metrópoles: IPPUR/UFRJ, 2011.

STEINBERGER, M.; BRUNA, G. C. Cidades médias: elos do urbano-regional e do público-privado. In: ANDRADE, T. A.; SERRA, R. V. Cidades Médias Brasileiras. Rio de Janeiro: IPEA, 2001.

TINEU, R. A. Desconcentração industrial da Região Metropolitana de São Paulo e seus efeitos sobre as Regiōes Administrativas de Campinas, São José dos Campos e Sorocaba no período de 1990 a 2005. Anais do $1^{o}$ Simpósio de Pós-Graduação em Geografia do Estado de São Paulo. Rio Claro: Ed. Unesp, 2008.

VAINER, C. B. Pátria, empresa e mercadoria: Notas sobre a estratégia discursiva do Planejamento Estratégico Urbano. In: ARANTES, O.; VAINER, C. B.; MARICATO, E. A Cidade do Pensamento Único: desmanchando consensos. Petrópolis: Vozes, 2000.

A B S T R A C T The paper examines the scope of the Statute of the City as a new regulation act of Brazilian urban policy based on the comparative study of contemporary processes in three medium-sized cities in São Paulo State (Piracicaba, Bauru and Rio Claro). The study analyzes three complementary dimensions: economic, urban and politicalinstitutional. It observes the existence of endogenous and exogenous obstacles, which have been conditioning urban policies and hindering the implementation of the directives of newly approved Master Plans. Despite the expressive incorporation of instruments of the Statute of the City, many of them has neither been implemented nor regulated. That scenario can be generalized as prevalent in Brazil and refers to contemporary standards of regional and urban development.

K E Y W O R D S Urban dynamics; medium-sized cities; statute of the city; participative master plans. 